\title{
Transposition of the Zorro2 Retrotransposon Is Activated by Miconazole in Candida albicans
}

\author{
Chun-xiang Zhu, ${ }^{a, \# ; \dagger}$ Lan Yan, ${ }^{a, \#}$ Xiao-juan Wang, ${ }^{b}$ Qi Miao, ${ }^{a}$ Xing-xing Li, ${ }^{a}$ Feng Yang, ${ }^{a}$ \\ Yong-bing Cao, ${ }^{a}$ Ping-hui Gao, ${ }^{a}$ Xin-ling $\mathrm{Bi},{ }^{*, c}$ and Yuan-ying Jiang ${ }^{*, a}$ \\ ${ }^{a}$ Center for New Drug Research, School of Pharmacy, Second Military Medical University; 325 Guohe Road, \\ Shanghai 200433, P.R. China: ${ }^{b}$ Department of Pharmacology, China Pharmaceutical University; 24 Tongjiaxiang \\ Road, Nanjing 210009, P.R. China: and ${ }^{c}$ Department of Dermatology, Changhai Hospital, Second Military Medical \\ University; 168 Changhai Road, Shanghai 200433, P.R. China. \\ Received June 24, 2013; accepted October 27, 2013
}

Zorro2 is a member of a non-long terminal repeat (LTR) retrotransposon family in Candida albicans, but as yet no clear evidence has been provided to establish either transcription or transposition activity for Zorro2. In this study, the relative expression changes of two open reading frames in Zorro2, ORF19.7274 and $O R F 19.7275$, were examined in response to miconazole (MCZ), and were found to be increased by this treatment. As well, the copy number and the transcripts of Zorro2 in MCZ-induced resistant daughter strains were increased compared to the parental strain, indicating that transposition of Zorro2 occurred during long-term MCZ treatment. Intriguingly, the transcription activity of Zorro2 retrotransposons was significantly inhibited when the cells were treated with MCZ together with antioxidant $N$-acetyl-L-cysteine (NAC). As both the level of intracellular reactive oxygen species (ROS) and the expression of genes involving DNA repair activated by MCZ were reduced when combined with the treatment of NAC, we propose that the damage caused by accumulation of ROS under MCZ stress is a major reason for the transcription and transposition activation of the Zorro2 retrotransposon.

Key words Candida albicans; retrotransposon; miconazole; Zorro2

Candida albicans is a pleiomorphic fungus that can exist as either a commensal or an opportunistic pathogen and is capable of causing superficial to life-threatening infection in human beings. Nowadays, with the widespread application of immunosuppressive therapy, clinical infections by C. albicans have become more common. ${ }^{1,2)}$ C. albicans cells can be cleared through phagocytosis and the respiratory burst involving reactive oxygen species (ROS) in phagocytes. ${ }^{3)}$ However, an impressive ability to adapt to environmental insults, including oxidative stress, helps $C$. albicans escape the immune system and facilitates a high incidence of resistance to azole antifungal agents in C. albicans. ${ }^{4}$

In recent years, transposons, particularly retrotransposons, have been found to play an important role in genetic evolution. Retrotransposons are mobile genetic elements capable of transposition via RNA intermediates. ${ }^{5)}$ The autonomous retrotransposons, which are capable of independent movement, consist of two sub-types, the long terminal repeat (LTR) retrotransposons and the non-LTR retrotransposons. Both of these classes contain one or two open reading frames (ORFs), which encode all the protein functions needed for retrotransposition, such as reverse transcriptase, endonuclease, integrase, etc. The most important difference between the two classes is that the latter lacks the LTR sequence. The non-LTR retrotransposons don't carry directly repeated sequences at their ends. Instead, they are often characterized by $3^{\prime}$-poly-A tails or $3^{\prime}$ tandem repeats.

There are a large number of retrotransposons in eukaryotic genomes. However, the incidence of transposition is very low.

\footnotetext{
The authors declare no conflict of interest.

\# These authors contributed equally to this work.

${ }^{\dagger}$ Present address: Department of Pharmacology, Changzhou Wujin People's Hospital; 2 Yongning North Road, Changzhou 213002, P.R. China.
}

It is estimated that the frequency of spontaneous transposition of Tyl elements in Saccharomyces cerevisiae varies among strains at rates of $10^{-5}-10^{-7} /$ element per generation. ${ }^{6)}$ The stability is due to the evolution of defense system. Researchers have shown that DNA methylation, covalent modification of histones, and small molecule interfering RNAs can restrict the activity of transposons. ${ }^{7-9)}$ Currently it has been reported that DNA damage is an important reason for activating transcription and transposition of yeast Ty retrotransposons. ${ }^{10)}$ Stress conditions such as UV light, X-rays, nitrogen starvation, carcinogens and low temperature may increase the transposition activity of Ty1. ${ }^{11-14)}$

In $C$. albicans, the activitation of retrotransposons has so far been found only under conditions of temperature shifts. Tca 2 and Tca 5 are transcriptionally activated by a temperature shift from $27^{\circ} \mathrm{C}$ to $37^{\circ} \mathrm{C}$ and the transposed copies of Tca 2 are integrated at several new positions in the genome. ${ }^{15,16)}$ Recently, non-LTR retrotransposons, the Zorros, have been identified in $C$. albicans. Only Zorro3 was full length; the other two, Zorro1 and Zorro2, were truncated in $5^{\prime}$ or degenerate and without long poly-A tracts or $3^{\prime}$ tandem repeat in the 3' UTR. Interestingly, unlike most non-LTR retrotransposons, the Zorros are present in few copies per genomic. Zorrol and Zorro3 are also temperature-dependent rertrotransposons in C. albicans. However, though Zorro1 and Zorro2 are found closer to each other, ${ }^{17}$ no clear evidence has been provided to prove the transcription or transposition activity for Zorro2 retrortransposon.

In this study, the activation of the Zorro2 retrotransposon was explored. The expression of the protein-encoded regions of Zorro2, ORF19.7274 and ORF19.7275, were activated by the treatment of miconazole (MCZ). The copy number and the transcripts of Zorro2 in laboratory-induced MCZ-resistant strains were also increased. The antioxidant $N$-acetyl-L-cys- 
teine (NAC) inhibited the transcription activity of Zorro2. Both the level of intracellular ROS, and the expression of genes involving DNA damage repair activated by MCZ, were reduced when combined with NAC treatment. Our findings suggested that the treatment of MCZ resulted in the transcription and transposition activation of the Zorro2 retrotransposon.

\section{MATERIALS AND METHODS}

Strains and Culture Conditions C. albicans SC5314 was kindly provided by Dr. William A Fonzi from Department of Microbiology and Immunology Georgetown University (Washington, U.S.A.). Three strains (sc-m1, sc-m2, and sc-m3) were derived from SC5314 under the pressure of MCZ for a month in liquid complete medium consisting of $1 \%(\mathrm{w} / \mathrm{v})$ yeast extract, $2 \%(\mathrm{w} / \mathrm{v})$ peptone and $2 \%(\mathrm{w} / \mathrm{v})$ dextrose (YPD). The strategy for induction of drug resistance was performed as described previously ${ }^{18)}$ with some modifications. A single colony of $C$. albicans SC5314 was inoculated into $10 \mathrm{~mL}$ of YPD broth and incubated overnight at $30^{\circ} \mathrm{C}$ with shaking (200 rpm). An aliquot of this culture containing $10^{6}$ cells was then transferred to $10 \mathrm{~mL}$ of YPD broth containing $\mathrm{MCZ}$ at twice the most recently measured $80 \%$ minimum inhibitory concentration $\left(\mathrm{MIC}_{80}\right)$, and incubated at $30^{\circ} \mathrm{C}$ with shaking (200 rpm). When the cultures reached a density of about $10^{8}$ cells/mL, aliquots containing $10^{6}$ cells were transferred into fresh YPD broth also containing $\mathrm{MCZ}$ at twice the most recently measured $\mathrm{MIC}_{80}$ and incubated as described above.

Sample Preparation Hydrogen peroxide $\left(\mathrm{H}_{2} \mathrm{O}_{2}\right)$; Azoles; Hypertonic treatment: C. albicans SC5314 cells in earlylogarithmic phase at an OD of 0.2 in YPD medium were subjected to $5 \mathrm{~mm} \mathrm{H}_{2} \mathrm{O}_{2}, 24 \mu \mathrm{g} / \mathrm{mL}$ of $\mathrm{MCZ}, 250 \mu \mathrm{g} / \mathrm{mL}$ of fluconazole (FLC), $250 \mu \mathrm{g} / \mathrm{mL}$ of itraconazole (ICZ), $156 \mu \mathrm{g} / \mathrm{mL}$ of ketoconazole (KCZ), $0.6 \mathrm{M} \mathrm{NaCl}$ or $1 \mathrm{~m}$ sobitol, respectively. Cells without any treatment were used as a control. Cells were grown at $30^{\circ} \mathrm{C}$ and collected after $3 \mathrm{~h}$ and $6 \mathrm{~h}$ treatment.

The combination of NAC and MCZ: C. albicans SC5314 cells in early-logarithmic phase at an optical density (OD) of 0.1 were transferred to fresh YPD medium containing $40 \mathrm{~mm}$ NAC. Cells without NAC treatment were used as a control. Both the control and NAC-treated cells were grown to an $\mathrm{OD}_{600}$ of 0.2 , followed by resuspension in an equal volume of fresh YPD medium with or without $24 \mu \mathrm{g} / \mathrm{mL}$ of MCZ. Cells were collected after $6 \mathrm{~h}$ culture.

RNA Isolation and Real-Time Reverse Transcription Polymerase Chain Reaction (RT-PCR) Analysis Total RNA was extracted from C. albicans SC5314 with or without the treatments using Fungal RNAout kit (TIANDS, China). Reverse transcription was performed in a total volume of $20 \mu \mathrm{L}$ with Avian Myeloblastosis Virus reverse transcripase (TaKaRa, Dalian, China), random primer (6-mer) (TaKaRa) and $1 \mu \mathrm{g}$ of total RNA, followed by the condition of $30^{\circ} \mathrm{C}$ for $10 \mathrm{~min}, 45^{\circ} \mathrm{C}$ for $15 \mathrm{~min}$, and $99^{\circ} \mathrm{C}$ for $2 \mathrm{~min}$, as recommended by the manufacturer. Real-time PCR reactions were performed with SYBR Green I (TaKaRa), using the LightCycler RealTime PCR system (Roche Molecular Biochemical). The oligos used in the real-time RT-PCR assay are listed in Table 1. The thermal cycling conditions comprised an initial step at $95^{\circ} \mathrm{C}$ for $10 \mathrm{~s}$, followed by 40 cycles at $95^{\circ} \mathrm{C}$ for $10 \mathrm{~s}, 62^{\circ} \mathrm{C}$ for $20 \mathrm{~s}$, and $72^{\circ} \mathrm{C}$ for $15 \mathrm{~s}$. The $C_{\mathrm{T}}$ value of $18 \mathrm{~S}$ rRNA was subtracted
Table 1. Primers Used in This Study

\begin{tabular}{llc}
\hline \hline Primer name & \multicolumn{1}{c}{ Sequence $\left(5^{\prime} \rightarrow 3^{\prime}\right)$} & $\begin{array}{c}\text { Amplicon } \\
\text { size }(\mathrm{bp})\end{array}$ \\
\hline 18S rRNA-F & TCTTTCTTGATTTTGTGGGTGG & 150 \\
18S rRNA-R & TCGATAGTCCCTCTAAGAAGTG & \\
ORF19.7274-F & AGCCAAGTTCCCAAAAAGAC & 174 \\
ORF19.7274-R & AATGCTGGACCACACACACC & \\
ORF19.7275-F & ACCTTGCCACTGATAGAC & 143 \\
ORF19.7275-R & GTTAGTAGCCCAGATTTT & 130 \\
MSH2-F & CAAGCAATCCGAAGTTAT & 138 \\
MSH2-R & AATTTGGGTTGGGTGTAT & 135 \\
RAD50-F & CGAAGATTTGAGTGGGTTTG & 127 \\
RAD50-R & CGTTGTGCCTTGTATTTGCT & 127 \\
MRE11-F & AAGATTTGAGTGGGTTTGG & 100 \\
MRE11-R & GTTGTGCCTTGTATTTGCT & \\
RAD6-F & CCTAATAAACCACCACA & \\
RAD6-R & TAATGATTGAACCGATG & \\
RAD52-F & GGATTTCTATGGTTGTTCG & \\
RAD52-R & GTGAGTGCTTCCTTTTTAC & \\
DDR48-F & CGACGACAAAGACAAGAAC & \\
DDR48-R & AGAGCCAAATGAAGAGGAT & \\
YKU80-F & AGATGACGATGAAGAGGG & \\
YKU80-F & GGGATGTTGGTAAAGTGG & \\
SPO11-F & TATCAAAGAAACCGAGAC & \\
SPO11-R & TAATGACCACCCTAACCC & \\
\hline
\end{tabular}

from that of the gene of interest to obtain a $\Delta C_{\mathrm{T}}$ value. The $\Delta C_{\mathrm{T}}$ value of an arbitrary calibrator was subtracted from the $\Delta C_{\mathrm{T}}$ value of each sample to obtain a $\Delta \Delta C_{\mathrm{T}}$ value. The gene expression level relative to the calibrator was expressed as $2^{-\Delta \Delta C_{T}}$

Southern Blotting C. albicans genomic DNA samples were digested with $X b a \mathrm{I}$, electrophoresed through $0.8 \%$ agaroseD-5 (Sigma) for $2.5 \mathrm{~h}$, and then vacuum-transferred to hybond-N+ nylon membranes (Roche). Hybridization was performed with a $688 \mathrm{bp}$ Zorro2-containing DNA fragment at $42^{\circ} \mathrm{C}$ for $16 \mathrm{~h}$. The DNA fragment was obtained by PCR amplication using the primer, 5'-TGTGTTGGCGTA TGC AGA TG-3' and the primer 5'-GTT GCC GAGAGT GCC TTG TC-3'. The purified PCR product was labeled with DIG-High Prime (Roche). The detection was carried out using DIG-High Prime DNA Labeling and Detection Starter kit II according to the producer's manual (Roche).

Antifungal Susceptibility Test The broth microdilution method for in vitro antifungal sensitivity testing of $C$. albicans was performed as standard Clinical and Laboratory Standards Institute (CLSI, formerly NCCLS) (M27-A2). ${ }^{19}$ ) Briefly, cells were inoculated into wells of a 96-well plate containing serial two-fold dilutions of antifungal drugs in RPMI-1640 medium buffered to $\mathrm{pH} 7.0$ with morpholinepropanesulfonic acid (MOPS). The initial concentration of the fungal suspension in RPMI-1640 medium was $1 \times 10^{3}$ cells $/ \mathrm{mL}$, and the final concentration of MCZ, FLC, ICZ, and $\mathrm{KCZ}$ in wells was ranged from $0.0195 \mu \mathrm{g} / \mathrm{mL}$ to $10 \mu \mathrm{g} / \mathrm{mL}, 0.125 \mu \mathrm{g} / \mathrm{mL}$ to $64 \mu \mathrm{g} / \mathrm{mL}, 0.039 \mu \mathrm{g} / \mathrm{mL}$ to $20 \mu \mathrm{g} / \mathrm{mL}$, or $0.039 \mu \mathrm{g} / \mathrm{mL}$ to $20 \mu \mathrm{g} / \mathrm{mL}$, respectively. Optical density was measured at $630 \mathrm{~nm}$ after incubation for $48 \mathrm{~h}$ at $30^{\circ} \mathrm{C}$. The endpoints for $\mathrm{MIC}_{80}$ were determined as the lowest concentration that resulted in an $80 \%$ reduction in turbidity as compared to the drug-free control wells. 

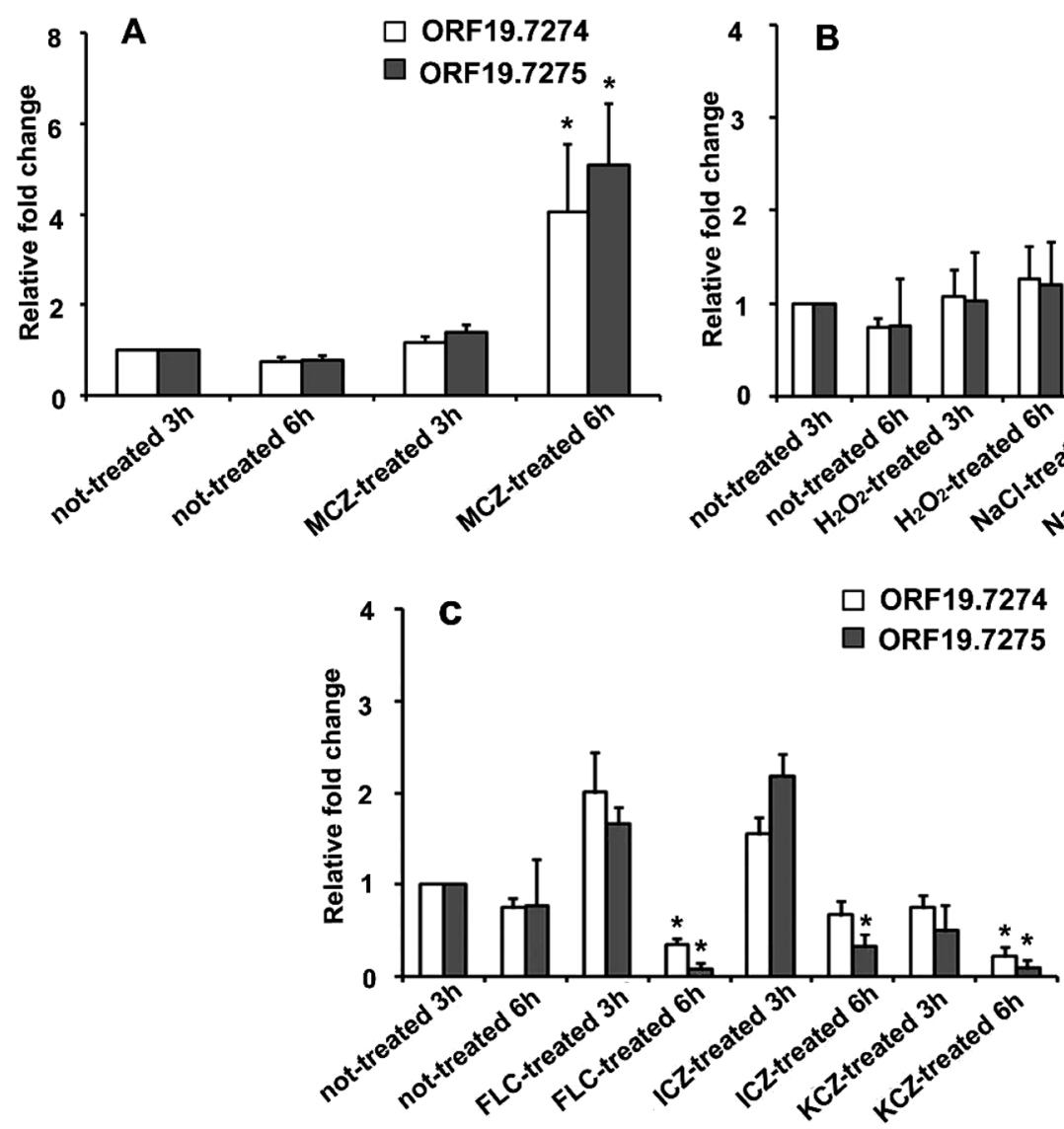

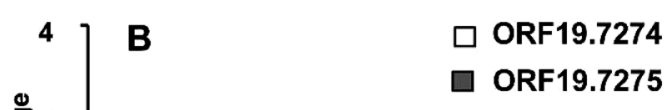

ORF19.7275

Fig. 1. The Transcriptional Activation of Two Predicted Protein-Encoding ORFs, ORF19.7274 and ORF19.7275, for Zorro2 Is Dependent on MCZ Treatment

C. albicans SC5314 cells were collected upon the treatment of azoles $\left(24 \mu \mathrm{g} / \mathrm{mL}\right.$ of MCZ, $250 \mu \mathrm{g} / \mathrm{mL}$ of FLC, $250 \mu \mathrm{g} / \mathrm{mL}$ of ICZ, $156 \mu \mathrm{g} / \mathrm{mL}$ of KCZ), $5 \mathrm{mM} \mathrm{H} \mathrm{O}_{2}$, or hypertonic stresses $\left(0.6 \mathrm{M} \mathrm{NaCl}\right.$ and $1 \mathrm{~m}$ sorbitol) after $3 \mathrm{~h}$ and $6 \mathrm{~h}$ incubation. Relative fold changes were calculated with $\Delta C_{\mathrm{T}}$ values of the targets with or without the treatments compared to those without the treatment after $3 \mathrm{~h}$ incubation. Data are shown as mean \pm S.D. $(n=3) . * p<0.05 v s$. not-treated $3 \mathrm{~h}$.

Spot assays were used to test the antifungal sensitivity as well. Briefly, C. albicans strains in mid-logarithmic phase were collected by centrifugation at $3000 \times \boldsymbol{g}$ for $5 \mathrm{~min}$, counted, and resuspended in $0.9 \%$ sterile normal saline at a concentration of $10^{7}$ cells $/ \mathrm{mL}$. A total of $4 \mu \mathrm{L}$ of these cultures was spotted in serial 10 -fold dilutions on drug-containing agar plate: MCZ $2 \mu \mathrm{g} / \mathrm{mL}$, FLC $4 \mu \mathrm{g} / \mathrm{mL}, \mathrm{ICZ} 4 \mu \mathrm{g} / \mathrm{mL}, \mathrm{KCZ}$ $2 \mu \mathrm{g} / \mathrm{mL}$. Growth differences were recorded after incubation of plates for $48 \mathrm{~h}$ at $30^{\circ} \mathrm{C}$.

Measurement of Intracellular ROS Production Intracellular ROS level was determined by $2^{\prime}, 7^{\prime}$-dichlorodihydrofluorescein diacetate, Sigma (DCFH-DA) as previously described. ${ }^{18)}$ Briefly, C. albicans cells were collected by centrifugation and resuspended in phosphate buffered saline (PBS) at an $\mathrm{OD}_{600}$ of 1.0. The cell suspension was incubated with $20 \mu \mathrm{g} / \mathrm{mL}$ DCFH-DA at $30^{\circ} \mathrm{C}$ for $30 \mathrm{~min}$. The cells were exposed to MCZ $(24 \mu \mathrm{g} / \mathrm{mL})$, NAC ( $40 \mathrm{~mm})$, or MCZ $(24 \mu \mathrm{g} /$ $\mathrm{mL})$ together with NAC $(40 \mathrm{~mm})$, and then incubated at $30^{\circ} \mathrm{C}$ with shaking $(200 \mathrm{rpm})$. At specified intervals, $100 \mu \mathrm{L}$ of cell suspensions were transferred to the wells of a flat-bottomed microplate (BMG Microplate, Black) to detect fluorescence intensity on the POLARstar Galaxy (BMG, Labtech, Offenburg, Germany) with excitation at $485 \mathrm{~nm}$ and emission at $520 \mathrm{~nm}$. Triplicate experiments were performed to generate a mean value. Alternatively, after treatments of the above agents for $3.5 \mathrm{~h}$, cell samples were examined with a $63 \times$ oil immersion lens under a TCS SP5 confocal laser-scanning microscope
(Leica Microsystems Trading Ltd.) with excitation at $485 \mathrm{~nm}$ and emission at $520 \mathrm{~nm}$. Micrograph pictures were acquired using LAS AF Lite program (Version 2.1.1 build 4443). Cells treated with $5 \mathrm{~mm} \mathrm{H}_{2} \mathrm{O}_{2}$ were performed as a control.

\section{RESULTS}

The Active Transcription of the Zorro2 Retrotransposon Depends on MCZ Transcriptional activity is required for transposition for all retro-elements. To test whether elements in Zorro2 are transcribed in response to treatments including $\mathrm{H}_{2} \mathrm{O}_{2}$, azoles, hypertonic $\mathrm{NaCl}$ and sorbitol, semi-quantitative RT-PCR was performed to analyze the relative mRNA expression changes of Zorro2 in strain SC5314. Two predicted protein-encoding regions required for retrotransposition in the Zorro2 retrotransposon were selected: ORF19.7274, with similarity to reverse transcriptase, and $O R F 19.7275$, with similarity to endonuclease. The relative expressions of ORF19.7274 and ORF19.7275 increased by more than 4 to 5 folds in response to $24 \mu \mathrm{g} / \mathrm{mL}$ of MCZ for $6 \mathrm{~h}$ (Fig. 1A), and didn't increase after $6 \mathrm{~h}$ incubation in the absence of MCZ (Fig. 1A) or in the presence of the other stresses including $5 \mathrm{mM} \mathrm{H}_{2} \mathrm{O}_{2}, 0.6 \mathrm{M} \mathrm{NaCl}$ or $1 \mathrm{M}$ sorbitol (Fig. 1B). However, the relative expressions of the two ORFs increased twice with the treatment of FLC or ICZ for $3 \mathrm{~h}$, but decreased after $6 \mathrm{~h}$, while those didn't changed with $\mathrm{KCZ}$ at $3 \mathrm{~h}$, but decreased at $6 \mathrm{~h}$ (Fig. 1C). These results suggested that the transcription of Zorro2 depended on stress 
A

B

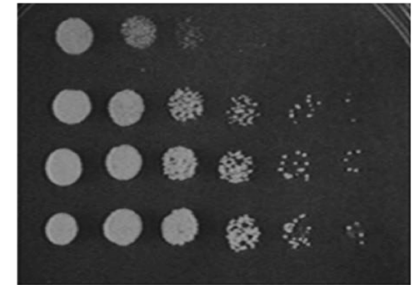

FLC $(4 \mu \mathrm{g} / \mathrm{mL})$

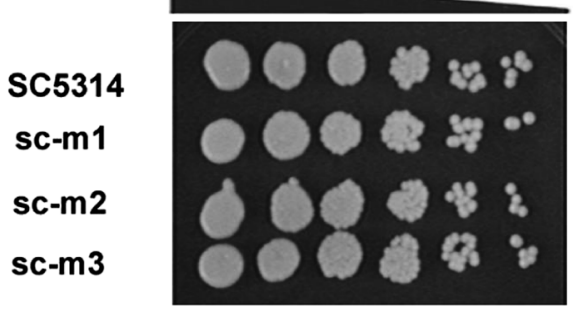

Control

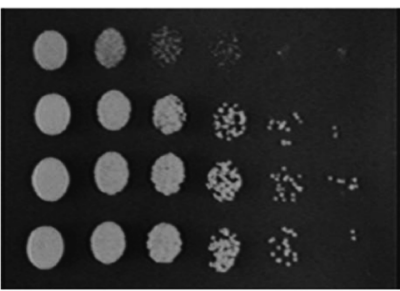

ICZ $(4 \mu \mathrm{g} / \mathrm{mL})$
$\operatorname{MIC} 80(\mu \mathrm{g} / \mathrm{mL})$

MCZ FLC ICZ KCZ

\begin{tabular}{ccccc}
\hline sC5314 & 0.02 & 0.5 & 4 & 0.156 \\
sc-m1 & 16 & 32 & 32 & 16 \\
sc-m2 & 20 & $>64$ & 64 & 20 \\
sc-m3 & 20 & $>64$ & 64 & 20 \\
\hline
\end{tabular}

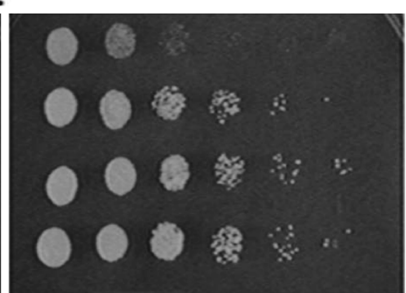

$\operatorname{MCZ}(2 \mu \mathrm{g} / \mathrm{mL})$

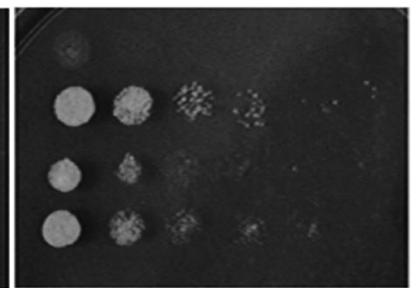

$\mathrm{KCZ}(2 \mu \mathrm{g} / \mathrm{mL})$

Fig. 2. Azole Sensitivity Testing for the Parental Strain SC5314 and the Three Derivative Strains of Long-Term MCZ Treatment (Sc-m1, Sc-m2, and Sc-m3)

(A) $\mathrm{The}_{\mathrm{MIC}}$ for azoles was tested by using broth microdilution in 96-well microtiter plates according to the Clinical and Laboratory Standards Institute. (B) The spot assay was performed to profile the growth difference with the treatment of MCZ, FLC, KCZ, or ICZ. Four microliters of ten-fold serial dilutions of each strain were spotted onto the plates in the presence of MCZ $(2 \mu \mathrm{g} / \mathrm{mL})$, FLC $(4 \mu \mathrm{g} / \mathrm{mL})$, ICZ $(4 \mu \mathrm{g} / \mathrm{mL})$, and KCZ $(2 \mu \mathrm{g} / \mathrm{mL})$. Growth differences were recorded after incubation for $48 \mathrm{~h}$ at $30^{\circ} \mathrm{C}$.
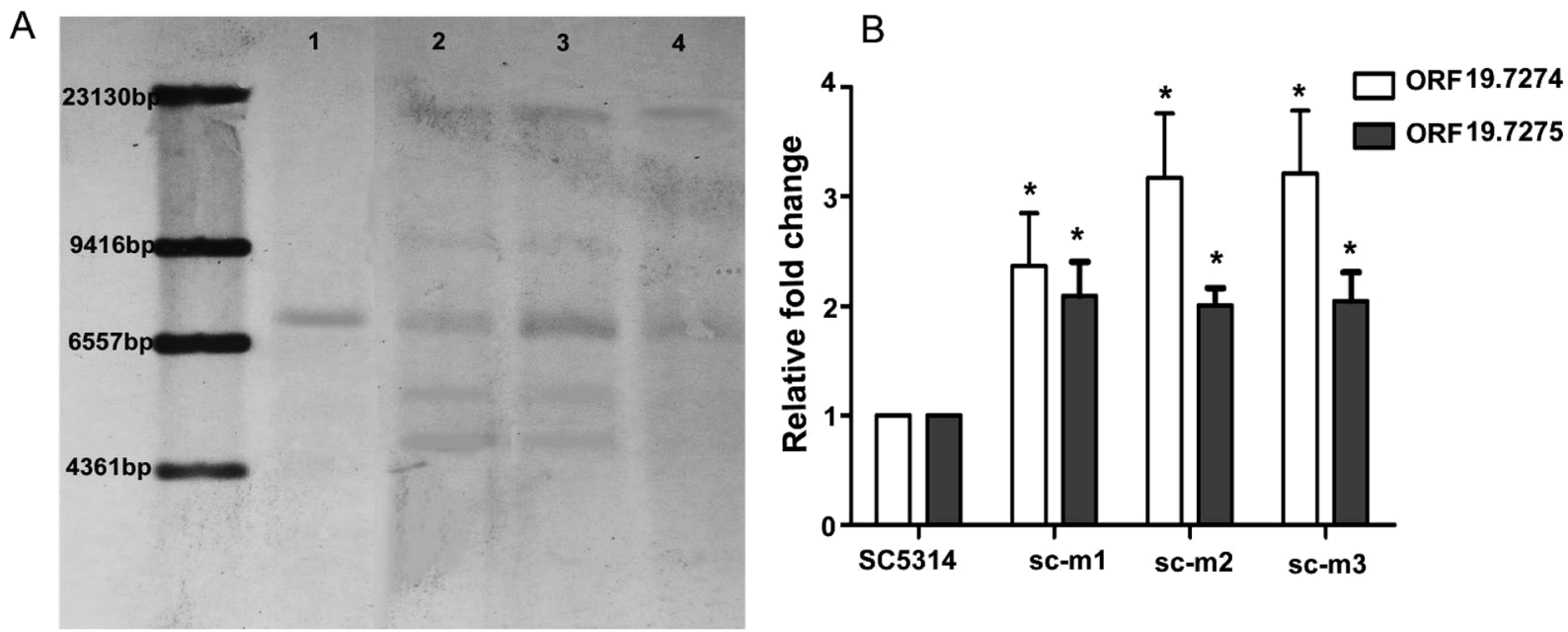

Fig. 3. The Zorro2 Retrotransposon Is Capable of Transposition

(A) Southern blotting analysis. XbaI-digested genomic DNA from the parental strain SC5314 and the three derivative strains of long-term MCZ treatment (sc-m1, sc-m2, and sc-m3) were hybridized to the internal region of Zorro2. Line 1: SC5314; line 2: sc-m1, line 3: sc-m2, line 4: sc-m3. (B) The transcription of the Zorro2 was activated in the derivative strains. Relative fold changes were calculated with $\Delta C_{\mathrm{T}}$ values of the derivative strains compared to the parental strain $\mathrm{SC} 5314 . * p<0.05 v s$. SC5314. 

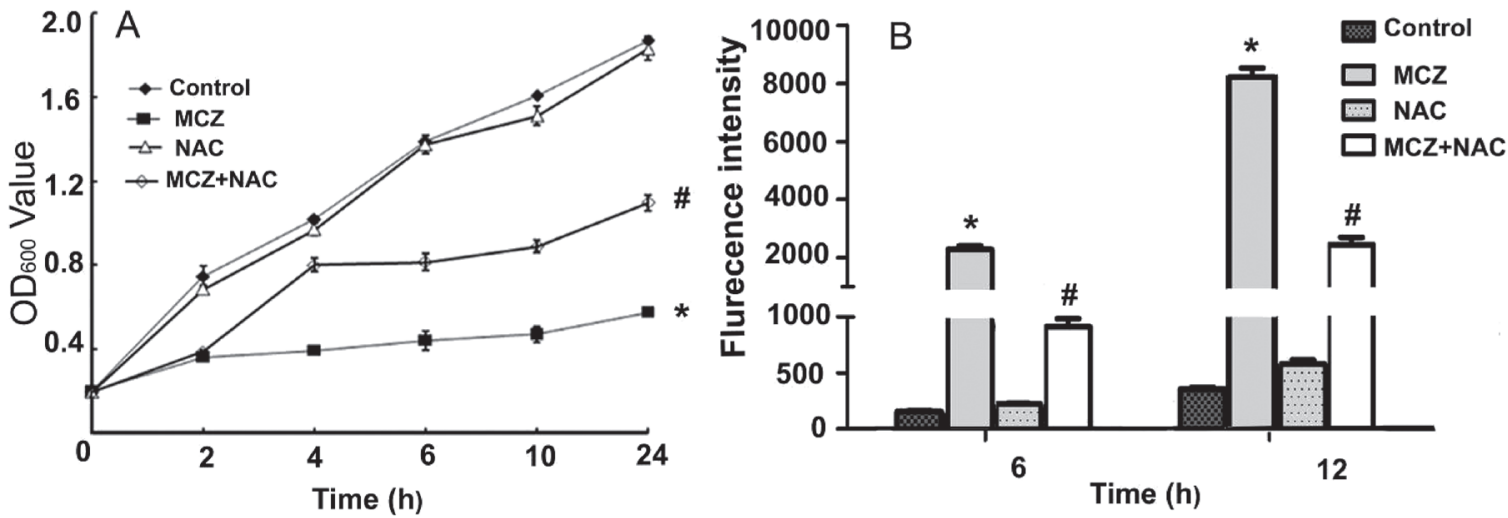

C

Bright field

Overlay

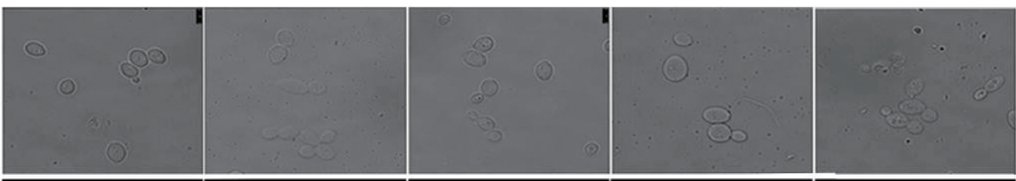

ROS

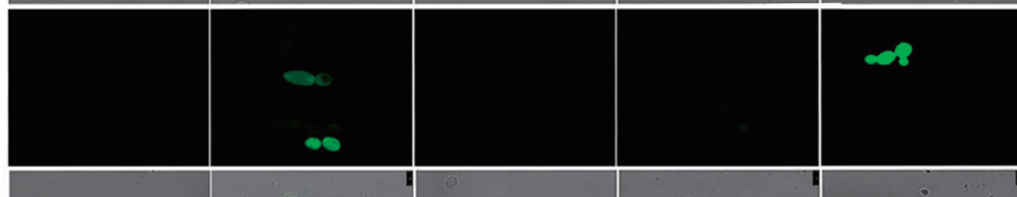

Overlay

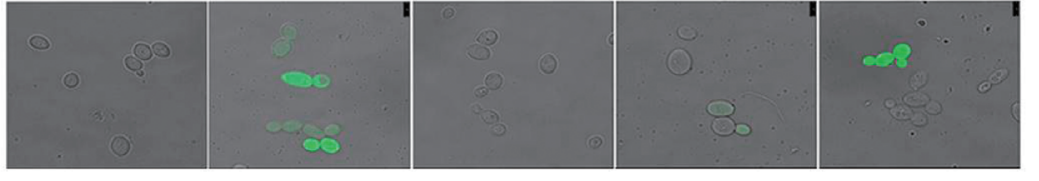

Control

MCZ

NAC

$M C Z+N A C$

$\mathrm{H}_{2} \mathrm{O}_{2}$
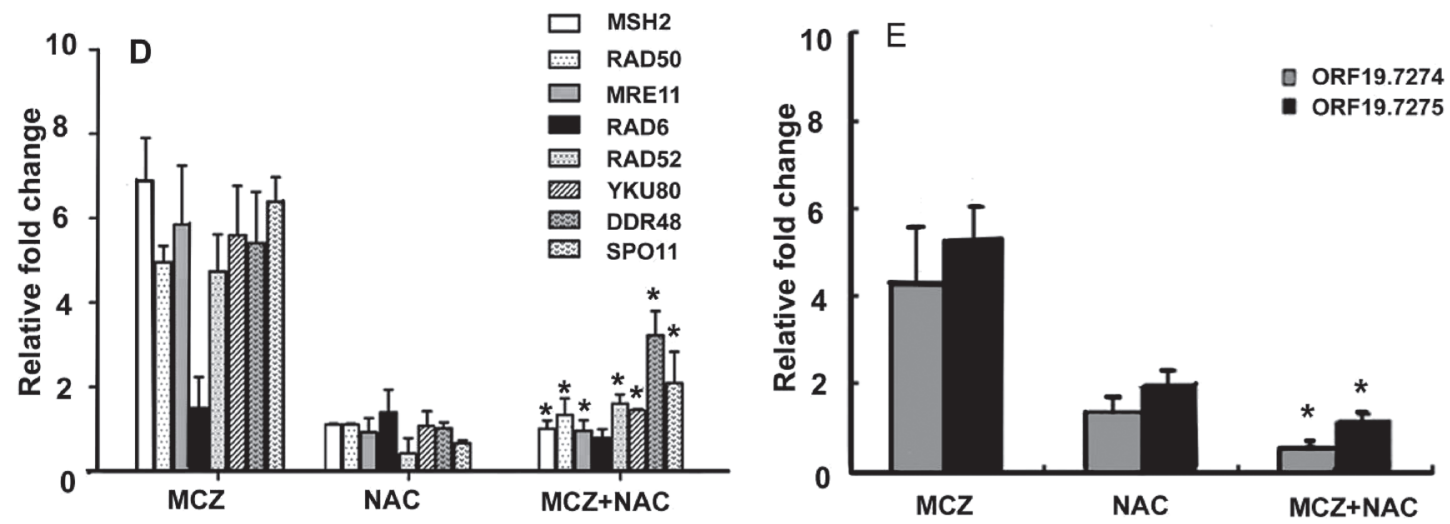

Fig. 4. Oxidative Damage Contributes to the Induction of Zorro2

(A) NAC rescued the growth of SC5314 in the presence of MCZ. A total of $40 \mathrm{~mm} \mathrm{NAC} \mathrm{was} \mathrm{added} \mathrm{to} \mathrm{the} \mathrm{cell} \mathrm{suspension} \mathrm{at} \mathrm{an} \mathrm{initial} \mathrm{OD}_{600}$ value of 0.1 . The cells were grown to an $\mathrm{OD}_{600}$ of 0.2 , followed by the addition of $24 \mu \mathrm{g} / \mathrm{mL}$ of $\mathrm{MCZ}$. OD 600 values were then recorded at the indicated time points. $* p<0.05 v s$. control group, ${ }^{\sharp} p<0.05$ vs. MCZ-treated group. (B) The increased endogenous ROS caused by MCZ in SC5314 was inhibited in the presence of NAC. Intercellular ROS level was detected under continuous treatment for $6 \mathrm{~h}$ and $12 \mathrm{~h}$ on the POLARstar Galaxy. ${ }^{*} p<0.05 v s$. control group, ${ }^{*} p<0.05$ vs. MCZ-treated group. (C) The intracellular ROS of each group were observed with confocal microscopy with excitation at $485 \mathrm{~nm}$ and emission at $520 \mathrm{~nm}$ after $3.5 \mathrm{~h}$ of treatment. Bar $=5 \mu \mathrm{m}$. The increased expression levels of genes involved in the DNA damage reparation (D) and the transcription activity for ORF19.7274 and ORF19.7275 (E) caused by MCZ were reduced in the presence of 40 mM NAC. Samples were collected under the continuous treatment for $6 \mathrm{~h}$. Relative fold changes were calculated with $\Delta C_{\mathrm{T}}$ values of genes in the strain with treatments compared to those in the strain without treatments. Data are shown as mean \pm S.D. $(n=3)$. ${ }^{*} p<0.05$ vs. MCZ-treated group.

caused by the antifungal MCZ and was independent of ergosterol biosynthesis pathway.

The Zorro2 Retrotransposon Is Capable of Transposition To evaluate the function of a retrotransposon, it is necessary to analyze whether the retrotransposon element is capable of performing all the steps of the replication cycle, including the generation of full-length double-stranded DNA molecules. In this study, considering the low incidence of transposition for retrotransposons during only one passage, three strains were selected after ca. $25 \mathrm{~d}$ of continuous MCZinduction. The induced daughter strains (sc-m1, sc-m2, and sc-m3) possessed high resistance to $\mathrm{MCZ}$ with $\mathrm{MIC}_{80}$ value increases of 800 to 1000 fold (Fig. 2A). Low concentrations of derivative strains still survived in the presence of $2 \mu \mathrm{g} / \mathrm{mL}$ of MCZ in contrast to the parental strain (Fig. 2B). Moreover, the MIC values of FLC, ICZ, and $\mathrm{KCZ}$ against the derivative strains were increased as well (Fig. 2A). The derivative strains survived in the presence of $4 \mu \mathrm{g} / \mathrm{mL}$ of FLC, $4 \mu \mathrm{g} / \mathrm{mL}$ of ICZ, and $2 \mu \mathrm{g} / \mathrm{mL}$ of $\mathrm{KCZ}$, while the parental strain did not (Fig. 2B). These results indicated that the MCZ-induced daughter strains were cross resistant to other azole agents.

Southern blotting was then performed in these three strains to investigate whether or not retrotransposon of Zorro2 occurred. As shown in Fig. 3A, with the internal probe of 
the Zorro2 retrotransposon, additional bands ranging from $20000 \mathrm{bp}$ to $5000 \mathrm{bp}$ were detected in the three induced MCZresistant strains, in comparison with the parental SC5314, which suggested that Zorro2 was capable of transposition in response to MCZ. Furthermore, the relative expressions of ORF19.7274 and ORF19.7275 in the derivative resistant strains were increased (Fig. 3B), suggesting a high transcriptional activity of Zorro2.

Oxidative Damage Contributes to the Induction of the Zorro2 Retrotransposon As the transcription and transposition activity of Zorro2 have been shown, we investigated whether the oxidative damage caused by MCZ was the reason for the transposition of Zorro2. The growth of SC5314 was first monitored to investigate the effect of NAC, an antioxidant, which is capable of eliminating cellular ROS, particular superoxide and hydrogen peroxide. There was no difference in growth between with or without treatment of NAC only. However, the sustained inhibition of growth caused by MCZ treatment was significantly rescued in the presence of both NAC and MCZ after $4 \mathrm{~h}$ incubation (Fig. 4A). We then examined whether or not the addition of NAC influenced intracellular ROS levels. The endogenous ROS level increased 15 to 24 fold after MCZ treatment for 6 to $12 \mathrm{~h}$ (Fig. 4B). As expected, with the addition of NAC together with $\mathrm{MCZ}$, the generation of endogenous ROS was significantly inhibited (Fig. 4B). These results were also confirmed by confocal microscopy. The fluorescence signals indicating intracellular ROS were observed inside of almost each MCZ-treated cell. However, the number of cells carrying fluorescence signal was significantly decreased in cells treated with MCZ and NAC. And their fluorescence intensity was relatively weak as well (Fig. 4C). These results provided evidence that the ROS were just generated inside the cells.

Furthermore, semi-quantitative RT-PCR was performed to analyze the expression change of genes involved in damage repair. As shown in Fig. 4D, the expression of repair-related genes including MSH2, RAD50, MRE11, RAD52, YKU80, $D D R 48$ and SPO11 were induced with the treatment of $\mathrm{MCZ}$ only, while the induction of those genes were significantly decreased when treated with MCZ in the presence of NAC. These results suggested that the addition of NAC reduced the degree of damage caused by MCZ. The effect of antioxidant NAC on the transcription activity of Zorro2 induced by $\mathrm{MCZ}$ stress was also observed. As expected, the induction of ORF19.7274 and ORF19.7275 by MCZ were reduced with the addition of NAC (Fig. 4E). Taken together, these results suggested that oxidative damage contributed to the transcriptional activation of Zorro2 retrotransposon.

\section{DISCUSSION}

Previous studies have reported that retrotransposons, including Tca2, Tca5, Zorro1 and Zorro3, can be activated by temperature changes in C. albicans, ${ }^{15-17,20)}$ but no evidence has yet been provided to prove the transcription or transposition activity for Zorro2 in C. albicans. In this study, we showed that the Zorro2 retrotransposon in $C$. albicans was transcriptionally activated and transposed in response to $\mathrm{MCZ}$, probably caused by the induction of endogenous ROS. This is the first time to report that an antifungal azole could participate in the regulation of retrotransposon activity in C. albicans.
To be functional, retrotransposons are transcriptionally activated first, and then are inserted at new positions in the host genome. The Zorro2 retrotransposon is different from the commonly studied LTR retrotransposons in structure, as the LTRs usually contain signals for promotion and termination of transcription that are required in the reverse transcription process. However, the lack of an LTR doesn't affect the process to transposition of Zorro2. We previously revealed that the copy numbers of ORF19.7274 and ORF19.7275 of the Zorro2 retrotransposon were increased in several clinical isolates compared with SC5314 by array-based comparative genomic hybridization analysis. ${ }^{21)}$ In this study, the transcription of Zorro2 was found up-regulated in strains in response to shorttime MCZ stress. Additional copies of Zorro2 were observed in the genome of derivative strains under long-term treatment of MCZ, suggesting that the Zorro2 has been transposed in the derivative strains with resistance to azole drugs. Our unreported data has shown that the transcription of ORF19.6469 in TCA11 retrotransposon and ORF19.2219 in TCA3 were also increased by more than 4 to 8 folds with the treatment of $\mathrm{MCZ}$ for $6 \mathrm{~h}$. But there were no additional copies of them observed in the genome of the derivative MCZ-resistant strains. These results further confirmed the correlation between MCZ and the transcriptionally activated and transposed Zorro2. It is reported that retrotransposons impart evolutionary plasticity to the genome, thereby contributing to the ability of cells to adapt to new environments. ${ }^{22)}$ Our results indicated that the transposition of Zorro2 could contribute the strains ability to survive under the pressure of the antifungal MCZ for genetic evolution.

The potential mechanism for Zorro2 transcription and transposition activity in response to $\mathrm{MCZ}$ stress was further investigated. As has been reported, the induction of endogenous ROS in $C$. albicans cells is one of the functions of MCZ, besides inhibition of the $14 \alpha$-demethylation of lanosterol. $^{23,24)}$ The increase of intracellular ROS production may block DNA replication and promote chromosomal loss. ${ }^{25}$ ) Retrotransposons can patch together broken chromosome ends, and provide dispersed regions of homology that facilitate chromosomal rearrangement. ${ }^{26,27)}$ It has been shown that Tyl is capable of transposition through a branch of the DNAdamage checkpoint pathway. ${ }^{28)}$ In this study, the addition of NAC reduced the transpositional activity of Zorro2 induced by the MCZ stress. Meanwhile, the widely up-regulated genes involved in DNA-damage repair in response to MCZ stress were all decreased when treated together with NAC. A plausible reason is that NAC could strongly inhibit endogenous ROS generation and protect the cells from oxidative damage. Therefore, it is possible that the generation and accumulation of intracellular ROS upon MCZ stress has a key role in activation the transcription level and transposition of Zorro2.

The increased transposition of Zorro2 could be a result of the MCZ treatment. But whether or not the increased copies of Zorro2 actually contribute to the increased azole resistance, further mechanistic experiments are required. Directly deleting the copy number of Zorro2 genetically or characterizing the specific locations of the transposed Zorro2, in the evolved MCZ-resistant strain, would be investigated in the future.

In conclusion, our study revealed that activation of Zorro2 retrotransposon in transcription and transposition upon $\mathrm{MCZ}$ treatment in $C$. albicans was caused by an oxidative damage 
repair mechanism. We propose that the Zorro2 in C. albicans genome is a potential internal element allowing genetic evolution.

Acknowledgments This work was supported by China National 973 Program (2013CB531602), Natural Science Foundation of China (31000079, 81173100, and 81330083). We would like to thank William A Fonzi (Immunology Georgetown University) for providing C. albicans SC5314. We also thank Malcolm Whiteway (Concordia University) for critical reading.

\section{REFERENCES}

1) Ivanovska $\mathrm{N}$, Hristova $\mathrm{M}$, Philipov $\mathrm{S}$. Immunosuppression and recovery of drug-impaired host resistance against Candida albicans infection by oxoglaucine. Pharmacol. Res., 41, 99-107 (2000).

2) White TC, Marr KA, Bowden RA. Clinical, cellular, and molecular factors that contribute to antifungal drug resistance. Clin. Microbiol. Rev., 11, 382-402 (1998).

3) Brakebusch M, Wintergerst U, Petropoulou T, Notheis G, Husfeld L, Belohradsky BH, Adam D. Bromelain is an accelerator of phagocytosis, respiratory burst and killing of Candida albicans by human granulocytes and monocytes. Eur. J. Med. Res., 6, 193-200 (2001).

4) Chauhan N, Latge JP, Calderone R. Signalling and oxidant adaptation in Candida albicans and Aspergillus fumigatus. Nat. Rev. Microbiol., 4, 435-444 (2006).

5) Zou S, Ke N, Kim JM, Voytas DF. The Saccharomyces retrotransposon Ty5 integrates preferentially into regions of silent chromatin at the telomeres and mating loci. Genes Dev., 10, 634-645 (1996).

6) Curcio MJ, Garfinkel DJ. Single-step selection for Tyl element retrotransposition. Proc. Natl. Acad. Sci. U.S.A., 88, 936-940 (1991).

7) Cheng $\mathrm{C}$, Daigen $M$, Hirochika $H$. Epigenetic regulation of the rice retrotransposon Tos17. Mol. Genet. Genomics, 276, 378-390 (2006).

8) Rehwinkel J, Natalin P, Stark A, Brennecke J, Cohen SM, Izaurralde E. Genome-wide analysis of mRNAs regulated by Drosha and Argonaute proteins in Drosophila melanogaster. Mol. Cell. Biol., 26, 2965-2975 (2006).

9) Slotkin RK, Martienssen R. Transposable elements and the epigenetic regulation of the genome. Nat. Rev. Genet., 8, 272-285 (2007).

10) Bradshaw VA, McEntee K. DNA damage activates transcription and transposition of yeast Ty retrotransposons. Mol. Gen. Genet., 218, 465-474 (1989).

11) Morillon A, Springer M, Lesage P. Activation of the Kss1 invasivefilamentous growth pathway induces Tyl transcription and retrotransposition in Saccharomyces cerevisiae. Mol. Cell. Biol., 20, 5766-5776 (2000).

12) Paquin CE, Williamson VM. Temperature effects on the rate of Ty transposition. Science, 226, 53-55 (1984).

13) Rolfe M, Spanos AD, Banks G. Induction of yeast Ty element tran- scription by ultraviolet light. Nature, 319, 339-340 (1986).

14) Pesheva M, Krastanova O, Staleva L, Dentcheva V, Hadzhitodorov M, Venkov P. The Tyl transposition assay: a new short-term test for detection of carcinogens. J. Microbiol. Methods, 61, 1-8 (2005).

15) Holton NJ, Goodwin TJ, Butler MI, Poulter RT. An active retrotransposon in Candida albicans. Nucleic Acids Res., 29, 4014 4024 (2001).

16) Plant EP, Goodwin TJ, Poulter RT. Tca5, a Ty5-like retrotransposon from Candida albicans. Yeast, 16, 1509-1518 (2000).

17) Goodwin TJ, Ormandy JE, Poulter RT. L1-like non-LTR retrotransposons in the yeast Candida albicans. Curr. Genet., 39, 83-91 (2001).

18) Yan L, Zhang JD, Cao YB, Gao PH, Jiang YY. Proteomic analysis reveals a metabolism shift in a laboratory fluconazole-resistant Candida albicans strain. J. Proteome Res., 6, 2248-2256 (2007).

19) Espinel-Ingroff A, Rodriguez-Tudela JL, Martinez-Suarez JV. Comparison of two alternative microdilution procedures with the National Committee for Clinical Laboratory Standards reference macrodilution method M27-P for in vitro testing of fluconazole-resistant and -susceptible isolates of Candida albicans. J. Clin. Microbiol., 33, 3154-3158 (1995)

20) Chen JY, Fonzi WA. A temperature-regulated, retrotransposonlike element from Candida albicans. J. Bacteriol., 174, 5624-5632 (1992).

21) Yang F, Yan TH, Rustchenko E, Gao PH, Wang Y, Yan L, Cao YY, Wang QJ, Ji H, Cao YB, Jiang YY. High-frequency genetic contents variations in clinical Candida albicans isolates. Biol. Pharm. Bull., 34, 624-631 (2011).

22) Wilke CM, Adams J. Fitness effects of Ty transposition in Saccharomyces cerevisiae. Genetics, 131, 31-42 (1992).

23) Yoshida Y. Cytochrome P450 of fungi: primary target for azole antifungal agents. Curr. Top. Med. Mycol., 2, 388-418 (1988).

24) Kobayashi D, Kondo K, Uehara N, Otokozawa S, Tsuji N, Yagihashi A, Watanabe N. Endogenous reactive oxygen species is an important mediator of miconazole antifungal effect. Antimicrob. Agents Chemother., 46, 3113-3117 (2002).

25) Lawrence CW, Hinkle DC. DNA polymerase zeta and the control of DNA damage induced mutagenesis in eukaryotes. Cancer Surv., 28, 21-31 (1996).

26) Dunham MJ, Badrane H, Ferea T, Adams J, Brown PO, Rosenzweig F, Botstein D. Characteristic genome rearrangements in experimental evolution of Saccharomyces cerevisiae. Proc. Natl. Acad. Sci. U.S.A., 99, 16144-16149 (2002).

27) Umezu K, Hiraoka M, Mori M, Maki H. Structural analysis of aberrant chromosomes that occur spontaneously in diploid Saccharomyces cerevisiae: retrotransposon Tyl plays a crucial role in chromosomal rearrangements. Genetics, 160, 97-110 (2002).

28) Scholes DT, Kenny AE, Gamache ER, Mou Z, Curcio MJ. Activation of a LTR-retrotransposon by telomere erosion. Proc. Natl. Acad. Sci. U.S.A., 100, 15736-15741 (2003). 